\title{
A web-based survey on factors for unvaccination and adverse reactions of SARS-CoV-2 vaccines in Chinese postoperative patients with breast cancer
}

\section{wang xiao}

Central South University

Minxue Shen

Central South University

\section{Qian Zhang}

Central South University

Xiaomin Wang

Central South University

Hanghao Zhang

Central South University

\section{Tingxuan Li}

Central South University

\section{Yuanping $\mathrm{Hu}$}

Central South University

\section{Fan Xia}

Central South University

Liqiu Liao ( $\sim$ aq301981@163.com )

Clinical Research Center For Breast Cancer (Xiangya Hospital)

\section{Research Article}

Keywords:

Posted Date: February 28th, 2022

DOI: https://doi.org/10.21203/rs.3.rs-1202932/v3

License: (9) (i) This work is licensed under a Creative Commons Attribution 4.0 International License. Read Full License 


\section{Abstract}

Vaccination against SARS-COV-2 has been the most important strategy for preventing infection and controlling pandemics of Coronavirus disease 2019 (COVID-19). But there is a lack of research on the pandemics in postoperative patients with breast cancer. We conducted a web-based questionnaire survey on SARS-CoV-2 vaccination in these populations. Univariate and multivariable logistic regression was used to estimate the associations. Among 947 valid online questionnaires, 341 (36.0\%) accepted SARS-CoV-2 vaccination, while 606 (64.0\%) were not. There were significant differences in age, current treatment, the time since surgery, and the symptoms of anxiety and depression between the two groups. We identified current treatment (odds ratio, $\mathrm{OR}=0.51$ for endocrine therapy; $95 \% \mathrm{Cl}$ : $0.29-0.89)$, the time since surgery (OR $=22.49$ for $1-2$ years; $95 \% \mathrm{Cl}: 12.31-41.10$; $\mathrm{OR}=8.49$ for $2-5$ years ; $95 \% \mathrm{Cl}: 4.98-14.46 ; \mathrm{OR}=1.79$ for $>5$ years $; 95 \% \mathrm{Cl}: 1.11-2.89)$, and the symptoms of depression (OR = 2.48; $95 \% \mathrm{Cl}: 1.19-5.15)$ as significant factors for unvaccination. The overall incidence of adverse reactions was $43.1 \%$, and the most common local and systemic adverse reactions were pain at the injection site (28.4\%) and fatigue (8.8\%), respectively. Postoperative patients with breast cancer have a lower rate of vaccination for SARS-CoV-2. Receiving treatment, a shorter time since surgery and symptom of depression were associated with unvaccination. But, about $76.6 \%$ of the unvaccinated participants were willing to be vaccinated when their breast cancer was stable. More importantly, a favorable safety profile of the vaccines is indicated.

\section{Introduction}

COVID-19, caused by the novel coronavirus SARS-CoV-2, has spread worldwide, is characterized by high mortality and unmanageable respiratory symptoms, especially in older patients and patients with pre-existing illnesses, such as cancers ${ }^{1-4}$. Cancer patients have a significantly higher risk of getting infected with COVID-19 because of their impaired immunity due to the disease or treatments ${ }^{5-9}$. Currently, vaccination against SARS-COV-2 has been the most important strategy for the prevention and control of COVID-19 ${ }^{10}$. Up to now, at least five different COVID-19 vaccines, mainly consisting of inactivated and protein subunit vaccines, have been approved for emergency use in China ${ }^{11}$. Although a strong willingness to vaccinate in the general population was reported by several cross-sectional studies, some reports showed a high hesitancy rate to receive a COVID-19 vaccine among oncologic patients, especially those still in the stage of tumor therapy ${ }^{12-15}$. Breast cancer, the most common female malignant tumor worldwide, is characterized by better survival ${ }^{16-18}$. According to GLOBOCAN statistics in 2020, nearly 2.3 million women have been diagnosed with breast cancer, and the incidence of this disease is increasing year by year in most parts of the world, including China ${ }^{16}$. However, studies that systematically investigated the safety profile after vaccination for SARS-CoV-2 in postoperative patients with breast cancer are scarce, and there is no clear recommendation for the timing for vaccination. Realworld data is urgently needed to address public concerns on the side effects of the vaccines. The purpose of the current study is to investigate the rate for SARS-CoV-2 vaccination, to know the concerns regarding SARS-CoV-2 vaccination, and the adverse reactions after vaccination among postoperative patients.

\section{Results}

From 4 September 2021 to 19 September 2021, 947 valid online questionnaires were collected from postoperative patients with breast cancer among women. The number of vaccinated and unvaccinated was 341 (36.0\%) and 606 (64.0\%), respectively. Of them,84.8\% received inactivated vaccine, $15.2 \%$ received protein subunit. $27.7 \%$ had completed the vaccination. Characteristics of the patients between unvaccinated and vaccinated for SARS-CoV-2 are shown in Table 1. There were significant differences between the two groups in age, current treatment, current state, concerns, anxiety, and depressive symptoms. 
Table 1

Characteristics of participants vaccinated and unvaccinated for SARS-CoV-2.

\begin{tabular}{|c|c|c|c|c|}
\hline Characteristic & $\begin{array}{l}\text { Total } \\
(\mathrm{N}=947)\end{array}$ & $\begin{array}{l}\text { Unvaccinated } \\
(n=606,64.0 \%)\end{array}$ & $\begin{array}{l}\text { Vaccinated } \\
(n=341,36.0 \%)\end{array}$ & $P$ \\
\hline Age (\%) & & & & 0.049 \\
\hline$\otimes 30 y$ & $11(1.2)$ & $8(1.3)$ & $3(0.9)$ & \\
\hline $30 y-39 y$ & $174(18.4)$ & $128(21.1)$ & $46(13.5)$ & \\
\hline $40 y-49 y$ & 395 (41.7) & 248 (40.9) & $147(43.1)$ & \\
\hline $50 y-60 y$ & 309 (32.6) & $186(30.7)$ & $123(36.1)$ & \\
\hline$₫ 60 y$ & $58(6.1)$ & $36(5.9)$ & $22(6.5)$ & \\
\hline Education (\%) & & & & 0.109 \\
\hline Primary /middle school & $386(40.8)$ & $247(40.8)$ & $139(40.8)$ & \\
\hline High school & 264 (27.9) & $157(25.9)$ & 107 (31.4) & \\
\hline College or above & 297 (31.4) & $202(33.3)$ & $95(27.9)$ & \\
\hline Marital status (\%) & & & & 0.284 \\
\hline Unmarried & $18(1.9)$ & $13(2.1)$ & $5(1.5)$ & \\
\hline Married & $848(89.5)$ & $534(88.1)$ & $314(92.1)$ & \\
\hline Divorced & $60(6.3)$ & $43(7.1)$ & $17(5.0)$ & \\
\hline Widowed & $21(2.2)$ & $16(2.6)$ & $5(1.5)$ & \\
\hline Current treatment (\%) & & & & $\varangle 0.001$ \\
\hline C.T. & 75 (7.9) & $60(9.9)$ & $15(4.4)$ & \\
\hline T.T. & $52(5.5)$ & $50(8.3)$ & $2(0.6)$ & \\
\hline R.T. & $13(1.4)$ & $13(2.1)$ & 0 & \\
\hline E.T. & $540(57.0)$ & $319(52.6)$ & $221(64.8)$ & \\
\hline C.M.T. & $51(5.4)$ & $31(5.1)$ & $20(5.9)$ & \\
\hline$\geq$ Two therapy methods & 79 (8.3) & 72 (11.9) & $7(2.1)$ & \\
\hline N.T. & $137(14.5)$ & $61(10.1)$ & $76(22.3)$ & \\
\hline Comorbidities (\%) & & & & 0.194 \\
\hline Hypertension & $90(9.5)$ & $52(8.6)$ & $38(11.1)$ & \\
\hline Hyperlipidemia & $81(8.6)$ & $46(7.6)$ & $35(10.3)$ & \\
\hline Obesity & $49(5.2)$ & $30(5.0)$ & $19(5.6)$ & \\
\hline Digestive diseases & $40(4.2)$ & $29(4.8)$ & $11(3.2)$ & \\
\hline Hepatitis & 36 (3.8) & $28(4.6)$ & $8(2.3)$ & \\
\hline
\end{tabular}

C.T.: only chemotherapy; T.T.: only HER2-targeted therapy(such as: Trastuzumab, Patuzumab, Pyrotinib and so on); R.T.: only radiation therapy; E.T.: only endocrine therapy(such as Tamoxifen, Toremifene, Anastrozole, Exemestane); C.M.T.: only Chinese medicine treatment; N.T.: Not receiving a treatment; Comorbidities: Other diseases besides breast cancer; 1-2 years: Including the second year after surgery; 2-5 years: The second year after surgery is not included; Consult a doctor: Consult a breast doctor or oncologist before the COVID-19 vaccination; GAD-2: two-item Generalized Anxiety Disorder; PHQ-2: two-item Patient Health Questionnaire. 


\begin{tabular}{|c|c|c|c|c|}
\hline Characteristic & $\begin{array}{l}\text { Total } \\
(\mathrm{N}=947)\end{array}$ & $\begin{array}{l}\text { Unvaccinated } \\
(n=606,64.0 \%)\end{array}$ & $\begin{array}{l}\text { Vaccinated } \\
(n=341,36.0 \%)\end{array}$ & $P$ \\
\hline Respiratory diseases & $31(3.3)$ & $20(3.3)$ & $11(3.2)$ & \\
\hline Time since surgery (\%) & & & & $\otimes 0.001$ \\
\hline$\otimes 1$ year & $317(33.5)$ & $290(47.9)$ & $27(7.9)$ & \\
\hline $1-2$ years & $208(22.0)$ & $160(26.4)$ & $48(14.1)$ & \\
\hline $2-5$ years & $305(32.2)$ & $125(20.6)$ & $180(52.8)$ & \\
\hline$\otimes 5$ years & $117(12.4)$ & $31(5.1)$ & $86(25.2)$ & \\
\hline Consult a doctor (\%) & $639(67.5)$ & $401(66.2)$ & $238(69.8)$ & 0.253 \\
\hline Anxiety (GAD-2 $\geq 3$ ) (\%) & $72(7.6)$ & $56(9.2)$ & $16(4.7)$ & 0.011 \\
\hline Depression (PHQ-2 $\geq 3$ ) (\%) & $84(8.9)$ & $68(11.2)$ & $16(4.7)$ & 0.001 \\
\hline \multicolumn{5}{|c|}{$\begin{array}{l}\text { C.T:: only chemotherapy; T.T.: only HER2-targeted therapy(such as: Trastuzumab, Patuzumab, Pyrotinib and so on); R.T.: only } \\
\text { radiation therapy; E.T.: only endocrine therapy(such as Tamoxifen, Toremifene, Anastrozole, Exemestane); C.M.T.: only } \\
\text { Chinese medicine treatment; N.T.: Not receiving a treatment; Comorbidities: Other diseases besides breast cancer; } 1-2 \text { years } \\
\text { Including the second year after surgery; } 2-5 \text { years: The second year after surgery is not included; Consult a doctor: Consult } \\
\text { breast doctor or oncologist before the COVID-19 vaccination; GAD-2: two-item Generalized Anxiety Disorder; PHQ-2: two-item } \\
\text { Patient Health Questionnaire. }\end{array}$} \\
\hline
\end{tabular}

Among the unvaccinated participants, the top three reasons for their decision included concerns about the vaccine-related adverse reactions (39.9\%), concerns about the conflict between SARS-CoV-2 and breast cancer treatment (38.3\%), and doctors don't recommend COVID-19 vaccines because of breast cancer (36.1\%). We then carried out a multivariable logistic regression and identified current treatment, the time since surgery, the symptoms of depression were significant factors for unvaccinated (Table 2). Patients receiving endocrine therapy were more likely to be vaccinated than untreated patients $(\mathrm{OR}=0.51$ for endocrine therapy; $95 \% \mathrm{Cl}$ : 0.29-0.89). In addition, the shorter of the time since surgery, patients were more likely to be vaccinated. We also investigated whether the breast cancer patients were willing to be vaccinated against SARS-CoV-2 if their disease was under control. $76.6 \%$ of the unvaccinated patients were willing to be vaccinated. These data demonstrated that the postoperative breast cancer patients had a strong willingness for vaccination if the disease was stable (Fig. 1). 
Factors for unvaccinated in participants.

\begin{tabular}{|c|c|c|c|c|}
\hline \multirow[t]{2}{*}{ Factors } & \multicolumn{2}{|l|}{ Univariate } & \multicolumn{2}{|l|}{ Multivariate } \\
\hline & OR $(95 \% \mathrm{Cl})$ & $P$ & OR $(95 \% \mathrm{Cl})$ & $P$ \\
\hline \multicolumn{5}{|l|}{ Age } \\
\hline$\varangle 30 y$ & Ref. & & Ref. & \\
\hline $30 y-39 y$ & $1.63(0.39,6.80)$ & 0.503 & $0.88(0.16,4.75)$ & 0.877 \\
\hline $40 y-49 y$ & $1.70(0.91,3.19)$ & 0.098 & $1.37(0.65,2.89)$ & 0.405 \\
\hline $50 y-60 y$ & $1.03(0.58,1.82)$ & 0.916 & $1.12(0.57,2.21)$ & 0.734 \\
\hline$\llbracket 60 y$ & $0.92(0.52,1.65)$ & 0.789 & $1.09(0.55,2.16)$ & 0.810 \\
\hline \multicolumn{5}{|l|}{ Current treatment } \\
\hline N.T. & Ref. & & Ref. & \\
\hline E.T. & $0.16(0.10,0.25)$ & $₫ 0.001$ & $0.51(0.29,0.89)$ & 0.017 \\
\hline others & $0.28(0.19,0.41)$ & $\varangle 0.001$ & $0.68(0.44,1.07)$ & 0.096 \\
\hline \multicolumn{5}{|l|}{ Time since surgery } \\
\hline \1 year & Ref. & & Ref. & \\
\hline $1-2$ years & $29.80(16.86,52.65)$ & $₫ 0.001$ & $22.49(12.31,41.10)$ & $\otimes 0.001$ \\
\hline $2-5$ years & $9.25(5.49,15.59)$ & $₫ 0.001$ & $8.49(4.98,14.46)$ & $\varangle 0.001$ \\
\hline$\otimes 5$ years & $1.93(1.20,3.08)$ & 0.006 & $1.79(1.11,2.89)$ & 0.017 \\
\hline Anxiety (GAD-2 $\geq 3$ ) & $2.07(1.17,3.67)$ & 0.013 & $0.83(0.38,1.82)$ & 0.649 \\
\hline Depression (PHQ-2 $\geq 3$ ) & $2.57(1.46,4.50)$ & 0.001 & $2.48(1.19,5.15)$ & 0.015 \\
\hline \multicolumn{5}{|c|}{$\begin{array}{l}\text { N.T.: Not receiving a treatment; E.T.: only endocrine therapy(such as Tamoxifen, Toremifene, Anastrozole, Exemestane); } \\
\text { others(C.T. or T.T. or R.T. or CMT or } \geq \text { Two therapy methods); CT: Chemotherapy; T.T.: HER2-targeted therapy(such as } \\
\text { Trastuzumab, Patuzumab, Pyrotinib and so on); R.T.: Radiation therapy; C.M.T.: Chinese medicine treatment; } 1-2 \text { years: } \\
\text { Including the second year after surgery; } 2-5 \text { years: The second year after surgery is not included; GAD-2: two-item Generalized } \\
\text { Anxiety Disorder; PHQ-2: two-item Patient Health Questionnaire; OR: odds ratio; Cl: confidence interval. }\end{array}$} \\
\hline
\end{tabular}

Table 3 showed reasons for getting vaccinated in participants. Vaccination of patients is mainly influenced by national policies and the status of breast cancer.

Table 3

Reasons for getting vaccinated in vaccinated participants.

\begin{tabular}{|ll|}
\hline Reasons & Total $(\mathbf{n}=\mathbf{3 4 1})$ \\
\hline Vaccination for national policy requirements (\%) & $122(35.8)$ \\
\hline the breast cancer condition is stable, and I asked for vaccination (\%) & $119(34.9)$ \\
\hline the breast cancer condition is stable, and doctors suggest vaccination (\%) & $96(28.2)$ \\
\hline The epidemic is still grim, and I ask for vaccination (\%) & $86(25.2)$ \\
\hline Follow other patients who have been vaccinated (\%) & $31(9.1)$ \\
\hline Others (\%) & $4(1.2)$ \\
\hline
\end{tabular}


Table 4 showed adverse reactions post-vaccination by types of vaccination among vaccinated patients. The overall incidence of adverse reactions was $43.1 \%$ (147/341), local adverse reactions $33.7 \%(115 / 341)$, and systemic adverse reactions $15.2 \%$

(52/341). 38.7\% (132/341) of the adverse reactions occurred after receiving the first shot, and no severe adverse reactions were reported. Besides, the inactivated vaccine and protein subunit vaccine showed similar traits of adverse reactions. There was no significant correlation between different treatment regimens and adverse reactions. In addition, we also investigated the changes in breast cancer conditions after vaccination. This seems to demonstrate that SARS-CoV-2 vaccination showed good safety for postoperative patients with breast cancer. 
Table 4

Adverse reactions of different types of vaccines and the relationship between different treatment regimens and adverse reactions.

\begin{tabular}{|c|c|c|c|c|c|c|c|c|c|c|c|}
\hline \multirow{2}{*}{$\begin{array}{l}\text { Adverse } \\
\text { reactions }\end{array}$} & \multirow{2}{*}{$\begin{array}{l}\text { Total } \\
(\mathrm{N}= \\
341)\end{array}$} & \multicolumn{3}{|c|}{ Type of vaccination } & \multicolumn{7}{|c|}{ Current treatment } \\
\hline & & $\begin{array}{l}\text { Inactivated } \\
\text { vaccine } \\
(n=289 \text {, } \\
84.8 \%)\end{array}$ & $\begin{array}{l}\text { Protein } \\
\text { subunit } \\
\text { vaccine } \\
(\mathrm{n}=52 \text {, } \\
15.2 \%)\end{array}$ & $P$ & $\begin{array}{l}\text { C.T. } \\
(n= \\
15)\end{array}$ & $\begin{array}{l}\text { T.T. } \\
(n \\
= \\
2)\end{array}$ & $\begin{array}{l}\text { E.T. } \\
(n= \\
221)\end{array}$ & $\begin{array}{l}\text { C.M.T. } \\
(n= \\
20)\end{array}$ & $\begin{array}{l}\geq \text { Two } \\
\text { therapy } \\
\text { Methods } \\
(n=7)\end{array}$ & $\begin{array}{l}\text { N.T. } \\
(n= \\
76)\end{array}$ & $P$ \\
\hline Any (\%) & $\begin{array}{l}147 \\
(43.1)\end{array}$ & $124(42.9)$ & $\begin{array}{l}23 \\
(44.2)\end{array}$ & 0.859 & $\begin{array}{l}6 \\
(40.0)\end{array}$ & 0 & $\begin{array}{l}101 \\
(45.7)\end{array}$ & $\begin{array}{l}8 \\
(40.0)\end{array}$ & $3(42.9)$ & $\begin{array}{l}29 \\
(38.2)\end{array}$ & 0.781 \\
\hline Local (\%) & $\begin{array}{l}115 \\
(33.7)\end{array}$ & 95 (32.9) & $\begin{array}{l}20 \\
(38.5)\end{array}$ & 0.433 & $\begin{array}{l}4 \\
(26.7)\end{array}$ & 0 & $\begin{array}{l}81 \\
(36.7)\end{array}$ & $\begin{array}{l}3 \\
(15.0)\end{array}$ & $2(28.6)$ & $\begin{array}{l}25 \\
(32.9)\end{array}$ & 0.414 \\
\hline Pain & $\begin{array}{l}97 \\
(28.4)\end{array}$ & $83(28.7)$ & $\begin{array}{l}14 \\
(26.9)\end{array}$ & 0.791 & $\begin{array}{l}3 \\
(20.0)\end{array}$ & 0 & $\begin{array}{l}69 \\
(31.2)\end{array}$ & $\begin{array}{l}2 \\
(10.0)\end{array}$ & $1(14.3)$ & $\begin{array}{l}22 \\
(28.9)\end{array}$ & 0.339 \\
\hline $\begin{array}{l}\text { Induration, } \\
\text { swelling }\end{array}$ & $\begin{array}{l}18 \\
(5.3)\end{array}$ & $13(4.5)$ & $5(9.6)$ & 0.168 & 0 & 0 & $\begin{array}{l}12 \\
(5.4)\end{array}$ & $\begin{array}{l}1 \\
(5.0)\end{array}$ & $1(14.3)$ & $\begin{array}{l}4 \\
(5.3)\end{array}$ & 0.666 \\
\hline Itch & $\begin{array}{l}14 \\
(4.1)\end{array}$ & $10(3.5)$ & $4(7.7)$ & 0.243 & $\begin{array}{l}1 \\
(6.7)\end{array}$ & 0 & $\begin{array}{l}8 \\
(3.6)\end{array}$ & 0 & 0 & $\begin{array}{l}5 \\
(6.6)\end{array}$ & 0.630 \\
\hline $\begin{array}{l}\text { Systemic } \\
(\%)\end{array}$ & $\begin{array}{l}52 \\
(15.2)\end{array}$ & $45(15.6)$ & $\begin{array}{l}7 \\
(13.5)\end{array}$ & 0.697 & $\begin{array}{l}3 \\
(20.0)\end{array}$ & 0 & $\begin{array}{l}33 \\
(14.9)\end{array}$ & $\begin{array}{l}17 \\
(85.0)\end{array}$ & $1(14.3)$ & $\begin{array}{l}10 \\
(13.2)\end{array}$ & $\nabla 0.001$ \\
\hline Fatigue & $\begin{array}{l}30 \\
(8.8)\end{array}$ & $28(9.7)$ & $2(3.8)$ & 0.284 & $\begin{array}{l}3 \\
(20.0)\end{array}$ & 0 & $\begin{array}{l}21 \\
(9.5)\end{array}$ & $\begin{array}{l}2 \\
(10.0)\end{array}$ & 0 & $\begin{array}{l}4 \\
(5.3)\end{array}$ & 0.457 \\
\hline $\begin{array}{l}\text { Headache, } \\
\text { dizziness }\end{array}$ & $\begin{array}{l}11 \\
(3.2)\end{array}$ & $8(2.8)$ & $3(5.8)$ & 0.227 & $\begin{array}{l}1 \\
(6.7)\end{array}$ & 0 & $\begin{array}{l}5 \\
(2.3)\end{array}$ & $\begin{array}{l}2 \\
(10.0)\end{array}$ & 0 & $\begin{array}{l}3 \\
(3.9)\end{array}$ & 0.227 \\
\hline $\begin{array}{l}\text { Stuffy, } \\
\text { runny } \\
\text { nose }\end{array}$ & $\begin{array}{l}9 \\
(2.6)\end{array}$ & $8(2.8)$ & $1(1.9)$ & 1.000 & 0 & 0 & $\begin{array}{l}5 \\
(2.3)\end{array}$ & $\begin{array}{l}2 \\
(10.0)\end{array}$ & 0 & $\begin{array}{l}2 \\
(2.6)\end{array}$ & 0.373 \\
\hline Itch & $\begin{array}{l}7 \\
(2.1)\end{array}$ & $6(2.1)$ & $1(1.9)$ & 1.000 & $\begin{array}{l}1 \\
(6.7)\end{array}$ & 0 & $\begin{array}{l}5 \\
(2.3)\end{array}$ & 0 & $1(14.3)$ & 0 & 0.099 \\
\hline Rash & $\begin{array}{l}3 \\
(0.9)\end{array}$ & $2(0.7)$ & $1(1.9)$ & 0.392 & 0 & 0 & $\begin{array}{l}2 \\
(0.9)\end{array}$ & 0 & 0 & $\begin{array}{l}1 \\
(1.3)\end{array}$ & 1.000 \\
\hline Arthralgia & $\begin{array}{l}3 \\
(0.9)\end{array}$ & $2(0.7)$ & $1(1.9)$ & 0.392 & 0 & 0 & $\begin{array}{l}2 \\
(0.9)\end{array}$ & $\begin{array}{l}1 \\
(5.0)\end{array}$ & 0 & 0 & 0.406 \\
\hline Fever & $\begin{array}{l}3 \\
(0.9)\end{array}$ & $2(0.7)$ & $1(1.9)$ & 0.392 & 0 & 0 & $\begin{array}{l}2 \\
(0.9)\end{array}$ & $\begin{array}{l}1 \\
(5.0)\end{array}$ & 0 & 0 & 0.406 \\
\hline Diarrhoea & $\begin{array}{l}2 \\
(0.6)\end{array}$ & $2(0.7)$ & 0 & 1.000 & 0 & 0 & $\begin{array}{l}2 \\
(0.9)\end{array}$ & 0 & 0 & 0 & 1.000 \\
\hline $\begin{array}{l}\text { Appetite } \\
\text { impaired }\end{array}$ & $\begin{array}{l}2 \\
(0.6)\end{array}$ & $2(0.7)$ & 0 & 1.000 & 0 & 0 & $\begin{array}{l}1 \\
(0.5)\end{array}$ & $\begin{array}{l}1 \\
(5.0)\end{array}$ & 0 & 0 & 0.291 \\
\hline Other (\%) & $\begin{array}{l}6 \\
(1.8)\end{array}$ & $6(2.1)$ & 0 & 0.596 & $\begin{array}{l}1 \\
(6.7)\end{array}$ & 0 & $\begin{array}{l}4 \\
(1.8)\end{array}$ & 0 & 0 & 1 & 0.513 \\
\hline
\end{tabular}

\section{Discussion}


We conducted a cross-sectional study through social media and reported a relatively low rate of vaccination for SARS-CoV-2 in postoperative patients with breast cancer. Compared with the vaccinated group, the unvaccinated group showed a shorter time since surgery, more receiving treatment, more symptoms of anxiety and depression. Receiving breast cancer-related treatment, time since surgery and the symptoms of depression as significant factors for unvaccinated. A lower rate of vaccine-related adverse reactions was shown.

The unexpected visit of COVID-19 is a challenge in the field of oncology. Although the percentage of COVID-19 among oncologic patients was only $2 \%$, there are limited studies on COVID-19 vaccination in postoperative patients with breast cancer ${ }^{19}$. According to a large meta-analysis from Luo et al., statistically increased risk of death in COVID-19 patients with cancer versus those without was observed, with an OR of $1.90(95 \% \mathrm{Cl}: 1.57-2.30)^{3}$. A nationwide analysis has confirmed that patients with cancer have a higher risk of severe events (a composite endpoint defined as the percentage of patients being admitted to the intensive care unit requiring invasive ventilation, or death) (39\% vs. $8 \%$, hazard ratio $[\mathrm{HR}]=5.34 ; 95 \% \mathrm{Cl}: 1.80-16.18 ; P=0.0026)$ and deteriorated more rapidly than those without cancer (median time to severe events, 13 days vs. 43 days, $\mathrm{HR}=3.56 ; 95 \% \mathrm{Cl}$ : $1.65-7.69 ; P<0.0001)^{20}$. Meanwhile, they confirmed that patients who were undergoing chemotherapy or surgery over the past month had a higher risk of clinically severe events $(75 \% \text { vs. } 43 \%)^{20}$. This prompted the management of breast cancer has to change significantly during the COVID-19 pandemic, including modification of the treatment protocol, extended the waiting time for the breast surgery, and increased use of genomic profile analysis based on an international survey named EUBREAST ${ }^{21}$. At present, most clinicians use American surgeons from the American Society of Breast Surgeons (ASBrS), National Certification Program Breast Centers (NAPBC), National Comprehensive Cancer Network (NCCN), The Cancer Council(CoC), And the American College of Radiology (ACR) guidelines as the global COVID-19 clinical decision stream ${ }^{22}$.

So far, vaccination remains an important strategy to prevent infection and control the pandemic. An efficacious vaccine is considered essential to prevent further morbidity and mortality ${ }^{10}$. However, according to our survey, the vaccination rate of postoperative patients with breast cancer was only $36.0 \%$. And, only $27.7 \%$ completed the vaccination. This can be explained by the results presented in Table 2. For example, the time since surgery was closer, and they were more reluctant to be vaccinated. Most participants concerns about the vaccine-related adverse reactions or the conflict between SARS-CoV-2 and breast cancer treatment. Antibodies could not be produced effectively because of the decreased function of the patient's immune system during chemotherapy. What's more, Patients with cancer are more vulnerable to adverse outcomes from COVID-19, indicated by metaanalyses, and hospitalized patients with cancer with COVID-19 infection are at higher risk of mortality ${ }^{23-25}$. Therefore, according to the Clinical Practice Guidelines for Immune Disabled Vaccination issued by the American Association for Infectious Diseases (IDSA), we still recommend that patients be vaccinated two weeks before the start of chemotherapy and three months after the end of chemotherapy ${ }^{26}$. Besides, we can adopt some of the ASCO's recommendations about clinical oncology FAQs document to reduce the risk of infection in unvaccinated patients, such as 1 . Patients can collect routine laboratory samples and even inject chemotherapy drugs at home whenever possible. 2. For hormone receptor-positive breast cancer patients may be delayed for up to two months. About $77 \%$ of unvaccinated patients were willing to be vaccinated when the breast cancer was stable, which is lower than in the previous studies ${ }^{12}$. This might be related to our premise that breast cancer is stable.

Patients with breast cancer are susceptible to mental health problems, such as anxiety and depression ${ }^{27}$. A systematic review reported that the prevalence of depression and anxiety among breast cancer survivors was $9.4-66.1 \%$ and $17.9-33.3 \%$, respectively ${ }^{28}$. Moreover, breast cancer survivorship was positively associated with anxiety $(\mathrm{HR}=1.33 ; 95 \% \mathrm{Cl}$ : $1.29-1.36 ; P<$ $0.001)$, depression ( $\mathrm{HR}=1.35 ; 95 \% \mathrm{Cl}: 1.32-1.38 ; P<0.001)^{29}$. Depended on our findings, the unvaccinated group showed more significant anxiety $(9.2 \%$ vs. $4.7 \%, P=0.011)$ and depression $(11.2 \%$ vs. $4.7 \%, P=0.001)$ compare with the vaccinated group. Besides, patients who were in states of depression were more reluctant to be vaccinated. Therefore, we encouraged patients to keep effective communication with a breast surgeon or oncologist, such as increasing the frequency of follow-up and holding lectures on knowledge related to the epidemic. This will bring some benefits including professionally assessing the patient's ability to tolerate vaccines to determine the approximate time of vaccination and reduce unnecessary anxiety or depression about the vaccination. 
Although the main trials showed efficacy in more than $90 \%$ of individuals and a favorable safety in healthy but also older populations, current knowledge of the safety and efficacy of the authorized COVID-19 vaccines in patients with cancer, particularly those receiving active treatment is limited ${ }^{30}$. Most guidelines recommend COVID-19 vaccination for cancer patients and make general assumptions that benefits outweigh the risk ${ }^{31}$. Encouragingly, no other safety questions for cancer patients until now. Our survey showed a $43.1 \%$ incidence of adverse reactions, which is lower than the $76.1 \%$ incidence in cancer patients ${ }^{32}$. This may be caused by the small sample size, the bias in the patient recall, or the limited type of vaccination in our survey. Besides, the inactivated vaccine and protein subunit vaccine showed similar traits of adverse reactions. More importantly, these adverse reactions were mild and self-limiting, such as pain, fatigue, hardening, and swelling at the injection site, and no severe adverse reactions were reported. This generally agrees with previous findings ${ }^{32,33}$. The above results suggested the COVID19 vaccination has a good safety feature in postoperative patients with breast cancer. So, we advocate that postoperative patients with breast cancer in good physical condition should accept COVID-19 vaccination as soon as possible, because delayed vaccination may place the vulnerable group at an increased risk of infection. But breast imaging at the disease assessment still needs to be done in hospitals with adequate resources because pandemics can be prolonged and potentially life-threatening in the long run.

Limitations of this study include the cross-sectional study design, recall bias from the participant, a lack of probability sampling, and a limited ability to indicate causality. However, the study has strengths, including large sample size, a systematic assessment of demographic, clinical, and psychological factors in the context of real-world clinical practice, and providing needed data to elucidate the factors associated with unvaccinated in postoperative patients with breast cancer. In addition, we are unable to observe its long-term effect on breast cancer due to the short period of widespread application of the novel coronavirus vaccine.

In conclusion, we reported a relatively low rate of vaccination for SARS-CoV-2 in postoperative patients with breast cancer. The unvaccinated group showed a shorter time since surgery, more receiving treatment, more symptoms of anxiety and depression than the vaccinated group. Time since surgery and the symptoms of depression as significant factors for unvaccinated. Our study implied a favorable safety profile of SARS-CoV-2 vaccines, and the benefits of vaccination should not be underappreciated.

\section{Methods}

Study design and population. A web-based cross-sectional study was conducted among women in a group of postoperative patients with breast cancer in China. We developed a self-administered online survey for the collection of data. The survey link was created through the Wen-Juan-Xing platform (Changsha Ranxing Information Technology Co., Ltd., Hunan, China), China's largest online survey platform. Postoperative Chinese female patients with breast cancer were recruited via social media platforms such as WeChat groups or Good Doctor Online Platform. We posted the link on the platform with no incentive measures. One submission of the questionnaire was allowed for a single I.P. address. For quality control, the questionnaire could not be submitted unless all required questions were answered. This survey was conducted between 4 Sept 2021 and 19 Sept 2021.This study adhered to the Declaration of Helsinki and was approved by the institutional research ethics boards of Xiangya Hospital, Central South University (Changsha, China).

Questionnaires. We developed the questionnaire based on interviews with breast cancer patients and revised the questionnaire after consultation with epidemiologists and breast surgeons according to the purpose of the current study.

We divided the questionnaire into four parts. In the first part, regardless of whether the patients were vaccinated, we collected demographic information, including age, education, marital status, and comorbidities.

In the second part, we collected information related to breast cancer including the current treatment (chemotherapy, HER2targeted therapy, radiation therapy, endocrine therapy, Chinese medicine treatment), the time since surgery.

The third part is about the survey of COVID-19 vaccination. To investigate the rate of SARS-CoV-2 vaccination, a single question, "Have you been vaccinated against the vaccination for SARS-CoV-2 and the type of vaccine?" was asked. At the same time, we asked participants if they had consulted a doctor before getting vaccinated and what types of vaccine they were getting. Reasons for unvaccinated were also investigated, with the options as follows: "a lack of vaccines supply", "concern about breast cancer 
deterioration after vaccination", "concern about adverse reactions of the vaccine", "concern about interactions between the vaccine and treatment for breast cancer", "having another disease that is a contraindication", "don't belong to the vaccinated population", "unnecessary to be vaccinated because of good control of pandemic", and "other reasons."Meanwhile, the reasons for patients already vaccinated were investigated and the options as follows: "The epidemic prevention and control situation at home and abroad is still grim, and I ask for vaccination", "At present, the breast cancer condition is stable, and doctors suggest vaccination", "I thought the condition of breast cancer is stable and asked for vaccination", "Other patients have been vaccinated and ask for the vaccination themselves", "Vaccination for national policy requirements", "other reasons". Adverse reactions after SARS-CoV-2 vaccination, included local and systemic reactions, were measured by a single question that allows multiple answers "Did you have any adverse reactions after the vaccination" with several responses based on some vaccine-related meta-analysis or survey ${ }^{32,33}$.

In the last part, to assess the patient's mental well-being, the symptoms of depression and anxiety were measured by the two-item Patient Health Questionnaire (PHQ-2) and the two-item Generalized Anxiety Disorder (GAD-2), respectively, with three as the cutoff point for both scales 34,35 .

Statistical analysis. Categorical variables including demographic and clinical information, adverse reactions, and other patientreported outcomes were displayed as counts (\%) and compared using the Chi-square test or Fisher's exact test. Multivariable logistic regression was used to identify factors for unvaccinated, and odds ratio (OR) and 95\% confidence interval (Cl) were presented as the effect sizes. All data were analyzed with SPSS 23 (IBM, SPSS Statistics 23). P-value < 0.05 was considered statistically significant.

\section{Declarations}

\section{Acknowledgements}

The author wishes to express thanks to Xiangya Hospital Central South University (Shouman Wang, Yuhui Wu, Jian Hai, Juan Huang, Lei Guo, Na Luo, Yehong Kuang and Qiaolin Wang), the Second Xiangya Hospital of Central South University (Wenjun Yi, Feng Xu, and Haiyan Zou), Hunan Cancer Hospital (Ning Xie), Hunan Provincial People's Hospital (Chaojie Zhang and Xu Dai), the First People's Hospital of Changde City (Tao Wu), the First People's Hospital of Huaihua City (Li Ding), the First People's Hospital of Chenzhou City (Jie Yan and Xiongqiang Hu) and Huarong County People's Hospital (Taohong Shen) for disseminating the survey and to all participants for their assistance in the online survey.

\section{Author contributions}

Data collection: X.W., Q.Z., X.W., and H.Z.; design/concept: L.L., M.S.; writing and data analysis: M.S. and X.W.; funding: L.L.; data interpretation/revision/final approval: all authors.

\section{Additional information}

The corresponding author is responsible for submitting a competing interests statement on behalf of all authors of the paper.

Informed consent statement: Informed consent was obtained from all the participants for the study.

Data availability: All data generated or analysed during this study are included in this published article.

Competing interests The authors declare no competing interests.

Ethical declarations Reviewed and approved by the institutional research ethics boards of Xiangya Hospital, Central South University (Changsha, China).

Funding This work was supported by the National Natural Science Foundation of China (81974420). The funder did not participate in the study. 


\section{References}

1 Huang, C. et al. Clinical features of patients infected with 2019 novel coronavirus in Wuhan, China. The Lancet 395, 497-506, doi:10.1016/s0140-6736(20)30183-5 (2020).

2 Chen, N. et al. Epidemiological and clinical characteristics of 99 cases of 2019 novel coronavirus pneumonia in Wuhan, China: a descriptive study. The Lancet 395, 507-513, doi:10.1016/s0140-6736(20)30211-7 (2020).

3 Luo, L. et al. The potential association between common comorbidities and severity and mortality of coronavirus disease 2019: A pooled analysis. Clin Cardio/ 43, 1478-1493, doi:10.1002/clc.23465 (2020).

4 Dong, E., Du, H. \& Gardner, L. An interactive web-based dashboard to track COVID-19 in real time. The Lancet Infectious Diseases 20, 533-534, doi:10.1016/s1473-3099(20)30120-1 (2020).

$5 \quad$ Kamboj, M. \& Sepkowitz, K. A. Nosocomial infections in patients with cancer. Lancet Onco/ 10, 589-597, doi:10.1016/S1470-2045(09)70069-5 (2009).

$6 \mathrm{Li}, \mathrm{J}$. Y. et al. Selective depletion of regulatory T cell subsets by docetaxel treatment in patients with nonsmall cell lung cancer. J Immunol Res 2014, 286170, doi:10.1155/2014/286170 (2014).

7 Longbottom, E. R. et al. Features of Postoperative Immune Suppression Are Reversible With Interferon Gamma and Independent of Interleukin-6 Pathways. Ann Surg 264, 370-377, doi:10.1097/SLA.0000000000001484 (2016).

8 Sica, A. \& Massarotti, M. Myeloid suppressor cells in cancer and autoimmunity. J Autoimmun 85, 117-125, doi:10.1016/j.jaut.2017.07.010 (2017).

9 Schmidt, T. et al. Influence of physical activity on the immune system in breast cancer patients during chemotherapy. $J$ Cancer Res Clin Oncol 144, 579-586, doi:10.1007/s00432-017-2573-5 (2018).

10 Hodgson, S. H. et al. What defines an efficacious COVID-19 vaccine? A review of the challenges assessing the clinical efficacy of vaccines against SARS-CoV-2. The Lancet Infectious Diseases 21, e26-e35, doi:10.1016/s1473-3099(20)30773-8 (2021).

11 Callaway, E. The race for coronavirus vaccines: a graphical guide. Nature 580, 576-577, doi:10.1038/d41586-02001221-y (2020).

12 Lazarus, J. V. et al. A global survey of potential acceptance of a COVID-19 vaccine. Nat Med 27, 225-228, doi:10.1038/s41591-020-1124-9 (2021).

13 Wang, J. et al. Acceptance of COVID-19 Vaccination during the COVID-19 Pandemic in China. Vaccines (Basel) 8 , doi:10.3390/vaccines8030482 (2020).

14 Zhang, Y., Luo, X. \& Ma, Z. F. Willingness of the general population to accept and pay for COVID-19 vaccination during the early stages of COVID-19 pandemic: a nationally representative survey in mainland China. Hum Vaccin Immunother 17, 16221627, doi:10.1080/21645515.2020.1847585 (2021).

15 Barriere, J. et al. Acceptance of SARS-CoV-2 vaccination among French patients with cancer: a cross-sectional survey. Ann Oncol 32, 673-674, doi:10.1016/j.annonc.2021.01.066 (2021).

16 Sung, H. et al. Global Cancer Statistics 2020: GLOBOCAN Estimates of Incidence and Mortality Worldwide for 36 Cancers in 185 Countries. CA Cancer J Clin 71, 209-249, doi:10.3322/caac.21660 (2021).

17 Matsen, C. B. \& Neumayer, L. A. Breast cancer: a review for the general surgeon. JAMA Surg 148, 971-979, doi:10.1001/jamasurg.2013.3393 (2013).

Page $11 / 13$ 
18 Allemani, C. et al. Global surveillance of trends in cancer survival 2000-14 (CONCORD-3): analysis of individual records for 37513025 patients diagnosed with one of 18 cancers from 322 population-based registries in 71 countries. The Lancet 391 , 1023-1075, doi:10.1016/s0140-6736(17)33326-3 (2018).

19 Desai, A., Sachdeva, S., Parekh, T. \& Desai, R. COVID-19 and Cancer: Lessons From a Pooled Meta-Analysis. JCO Glob Oncol 6, 557-559, doi:10.1200/G0.20.00097 (2020).

20 Liang, W. et al. Cancer patients in SARS-CoV-2 infection: a nationwide analysis in China. Lancet Onco/ 21, 335-337, doi:10.1016/S1470-2045(20)30096-6 (2020).

21 Gasparri, M. L. et al. Changes in breast cancer management during the Corona Virus Disease 19 pandemic: An international survey of the European Breast Cancer Research Association of Surgical Trialists (EUBREAST). Breast 52, 110-115, doi:10.1016/j.breast.2020.05.006 (2020).

22 Dietz, J. R. et al. Recommendations for prioritization, treatment, and triage of breast cancer patients during the COVID19 pandemic. the COVID-19 pandemic breast cancer consortium. Breast Cancer Res Treat 181, 487-497, doi:10.1007/s10549-02005644-z (2020).

23 Izcovich, A. et al. Prognostic factors for severity and mortality in patients infected with COVID-19: A systematic review. PLoS One 15, e0241955, doi:10.1371/journal.pone.0241955 (2020).

24 Ribas, A. et al. Priority COVID-19 Vaccination for Patients with Cancer while Vaccine Supply Is Limited. Cancer Discov 11, 233-236, doi:10.1158/2159-8290.CD-20-1817 (2021).

25 Noor, F. M. \& Islam, M. M. Prevalence and Associated Risk Factors of Mortality Among COVID-19 Patients: A MetaAnalysis. J Community Health 45, 1270-1282, doi:10.1007/s10900-020-00920-x (2020).

26 Rubin, L. G. et al. 2013 IDSA clinical practice guideline for vaccination of the immunocompromised host. Clin Infect Dis 58, e44-100, doi:10.1093/cid/cit684 (2014).

27 Carreira, H. et al. Associations Between Breast Cancer Survivorship and Adverse Mental Health Outcomes: A Systematic Review. J Natl Cancer Inst 110, 1311-1327, doi:10.1093/jnci/djy177 (2018).

28 Maass, S. W., Roorda, C., Berendsen, A. J., Verhaak, P. F. \& de Bock, G. H. The prevalence of long-term symptoms of depression and anxiety after breast cancer treatment: A systematic review. Maturitas 82, 100-108, doi:10.1016/j.maturitas.2015.04.010 (2015).

29 Carreira, H., Williams, R., Funston, G., Stanway, S. \& Bhaskaran, K. Associations between breast cancer survivorship and adverse mental health outcomes: A matched population-based cohort study in the United Kingdom. PLoS Med 18, e1003504, doi:10.1371/journal.pmed.1003504 (2021).

30 Anderson, E. J. et al. Safety and Immunogenicity of SARS-CoV-2 mRNA-1273 Vaccine in Older Adults. N Engl J Med 383, 2427-2438, doi:10.1056/NEJMoa2028436 (2020).

31 Hwang, J. K., Zhang, T., Wang, A. Z. \& Li, Z. COVID-19 vaccines for patients with cancer: benefits likely outweigh risks. J Hematol Oncol 14, 38, doi:10.1186/s13045-021-01046-w (2021).

32 So, A. C. P. et al. COVID-19 Vaccine Safety in Cancer Patients: A Single Centre Experience. Cancers (Basel) 13, doi:10.3390/cancers13143573 (2021).

33 McDonald, I., Murray, S. M., Reynolds, C. J., Altmann, D. M. \& Boyton, R. J. Comparative systematic review and metaanalysis of reactogenicity, immunogenicity and efficacy of vaccines against SARS-CoV-2. NPJ Vaccines 6, 74, doi:10.1038/s41541-021-00336-1 (2021).

Page $12 / 13$ 
35 Plummer, F., Manea, L., Trepel, D. \& McMillan, D. Screening for anxiety disorders with the GAD-7 and GAD-2: a systematic review and diagnostic metaanalysis. Gen Hosp Psychiatry 39, 24-31, doi:10.1016/j.genhosppsych.2015.11.005 (2016).

\section{Figures}

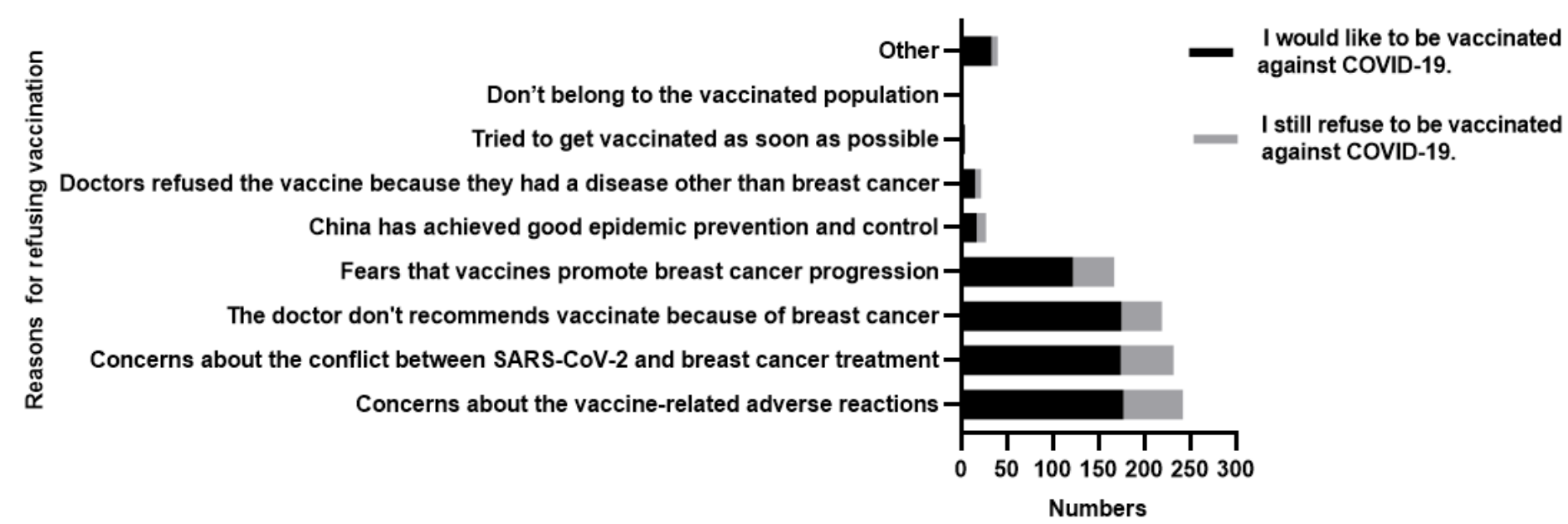

Figure 1

Reasons for unvaccinated and acceptance of vaccination. 